\title{
Moradas da Lagoa: Uma Vivência Comunitária e Produtiva
}

\author{
Tereza Cristina Pamponet Ribeiro Dantas \\ Mestranda do Mestrado Profissional e Multidisciplinar em Desenvolvimento \\ e Gestão Social pela Universidade Federal da Bahia - UFBA, \\ Av. Luis Viana Filho s/n $2^{\text {a }}$ avenida \\ Centro Administrativo \\ 41750-300 - Salvador-BA \\ tinapamponet@hotmail.com
}

\section{Resumo}

Este trabalho apresenta uma experiência da prática de gestão social numa intervenção de desenvolvimento territorial, buscando retratar as dinâmicas estabelecidas nas relações de cooperação e de conflito no contexto vivenciado, as quais vão promover a tão chamada "governança", através de novos padrões de interação entre os atores institucionais presentes: os órgãos governamentais, organizações da sociedade civil, empresas privadas e a comunidade. Para tanto, foi feita uma análise do processo da gestão social e das relações de produção e trabalho capitalista e, em alguns casos relação de produção pautada na economia popular solidária, as quais vivenciam lógicas e racionalidades diferentes e, em muitos momentos, contraditórias, embora estejam inseridas no contexto capitalista mercantilista. Neste contexto a lógica é utilitária e competitiva e sua racionalidade é instrumental; por outro lado existem iniciativas de economia popular que são norteadas pela lógica da reciprocidade e das relações de proximidade, tendo a racionalidade substantiva conformando as relações de produção e de trabalho. No final, são apontadas algumas questões interrogativas de um processo de intervenção no contexto capitalista de desenvolvimento.

Palavras-chave: Gestão Social. Participação. Estado. Economia Solidária.

\begin{abstract}
This paper presents a practical experience of management of social intervention in regional development, seeking to portray the momentum in the relations of cooperation and conflict in the live context, which will promote the so-called "governance", through new patterns of interaction between institutional actors present: government agencies, civil society organizations, private companies and community. Therefore, an analysis was made of the case management and social relations of capitalist production and work, and in some cases of food production for the local economy of solidarity, which experience different logics and rationalities, and many times contradictory, but are inserted in the mercantile capitalist context. In this context the rationale is utilitarian and competitive and its rationality is instrumental, on the other hand, there are initiatives of the popular economy that are driven by the logic of reciprocity and close relations, and substantive rationality shaping the relations of production and work. In the end, points out some issues of an interrogative process of intervention in the context of capitalist development.
\end{abstract}

Key-words: Social Management. Participation. State. Solidarity Economy. 


\section{Introdução: histórico da intervenção e do público beneficiário}

O Loteamento Moradas da Lagoa surgiu em 2002 de uma ação articulada e integrada entre o Governo do Estado da Bahia, com a participação das secretarias estaduais de Combate á Pobreza e às Desigualdades Sociais - SECOMP e a Secretaria de Trabalho, Assistência Social e Esporte; e o município de Salvador, através da Secretaria de Desenvolvimento Social, e do apoio de instituições da sociedade civil.

Geograficamente o Loteamento Moradas da Lagoa situa-se em Salvador, no Bairro de Coutos, limitando-se com os bairros de Valéria e fazenda Coutos III, distante $40 \mathrm{~km}$ do centro da cidade. O bairro de Coutos apresenta características próprias de bairros periféricos, no que se refere à insuficiência dos serviços básicos nas áreas de educação, saúde, habitação, segurança, não possuindo também espaços para lazer. A ausência de espaços públicos e de acesso de transporte dificulta o processo de socialização, fazendo com que ocorra uma regionalização dos moradores, pois poucos são aqueles que circulam por áreas distantes às suas moradias, mesmo no entorno de Coutos. Esse contexto particulariza a urbanização das cidades que, analisado por Milton Santos, remete às transformações do território pelo poderio econômico, aos modelos de desenvolvimento e à modernidade (Santos, 1996).

Os projetos, objeto dessa intervenção, estavam pautados em dois eixos estruturados: o acesso à moradia e a promoção de ações produtivas que viabilizem a geração de trabalho e renda para as famílias beneficiadas.

Essa intervenção teve como ponto de partida o atendimento a um dos mais graves problemas sociais enfrentados pela cidade do Salvador, a chamada "população de rua", parcela da população marcada pelo preconceito, pela violência, que vive literalmente nas ruas, sem abrigo, dormindo nas calçadas, túneis e sob viadutos, a depender da caridade pública.

A gravidade da situação vem exatamente da pluralidade de problemas que cada morador traz consigo, desde os materiais aos de saúde física e mental, a solidão, a desilusão, a baixa auto-estima, somados ao desajuste familiar e social, ao desemprego, a baixa qualificação e uma infinidade de outras mazelas, que culminam com a sua terrível exclusão social.

Buscando outras dimensões basilares temos a falta de moradia e o fato dessas pessoas não se sentirem cidadãos e, portanto, não incluídos na sociedade. Aí se situam o desejo de participar das decisões que dizem respeito às suas vidas, o desejo de ser ouvido e respeitado, de dispor de informações sobre as políticas inclusivas e de ter acesso às políticas sociais de saúde, educação, trabalho, renda e moradia.

O primeiro desafio estava colocado: Como buscar o surgimento de uma comunidade de cerca de 800 famílias, que vivenciam problemas de toda ordem, num espaço geográfico que já enfrenta a violência, o desemprego, a falta de oferta de serviços básicos?

A intervenção teve como primeira ação em 2002, o processo censitário das famílias em situação de rua, que contou com a participação de alguns de seus moradores no processo $\mathrm{d}$ a contagem. Após a conclusão do censo foi iniciada uma pesquisa diagnóstica, utilizando as etapas de abordagem, acolhimento e posteriormente a aplicação de um questionário semiestruturado, buscando dados quantitativos e qualitativos.

A pesquisa diagnosticou que majoritariamente essa população é formada por homens (77\%), sendo $98 \%$ de negros, onde um terço está na faixa etária de 25 e 39 anos, portanto no auge da idade produtiva. Mais da metade ou $56 \%$ são pessoas vindas do interior. Crianças com até 09 anos correspondem a 3\% do grupo e, na faixa etária entre 10 a 16 anos são 4\%. No outro extremo, são $21 \%$ os que têm mais de 50 anos de idade. Com relação às mulheres a idade média é de 33 anos, onde se verificou muitas delas grávidas.

Quanto à educação, a taxa de analfabetismo é de $18 \%$, concentrando na faixa que vai dos 20 a 49 anos, sendo que mais da metade da população pesquisada possui o nível fundamental incompleto. 
Em relação aos meios de sobrevivência, a maioria da população de rua vive da caridade das pessoas que dão esmolas e, em alguns casos, prestam pequenos serviços de biscate, apesar de muitos relatarem já terem tido uma profissão, na área da construção civil, de serviços gerais e manutenção industrial. Nesse quesito foi constatada a vontade de regressar ao mercado de trabalho, vislumbrando a possibilidade de sair dessa situação, marcada pelo preconceito e pela violência.

São várias as causas apontadas como determinantes para viverem nas ruas, desde desajustes familiares, como problema preponderante, como também, o uso elevado do álcool e drogas e o desemprego. Com relação ao núcleo familiar, os processos de erosão e desarticulação familiar são agravados pelas condições precárias e as tensões extremas que a pauperização gera no interior da família. Estes problemas estão alinhados a uma situação estrutural, representada pela falta de oportunidade de trabalho, carências das condições básicas de sobrevivência, devido a fragilidade ou ausência de políticas públicas efetivas e includentes.

Para Klisberg, o fortalecimento da família melhora o capital humano da sociedade e o desenvolvimento social, que são bases da estabilidade democrática. Ele ratifica essa proposição comentando: "Fortalecê-la é dar um passo efetivo para as possibilidades de desenvolvimento das potencialidades do ser humano, é dignificá-lo, é ampliar suas oportunidades, é aumentar sua liberdade real" (2003, p.67).

A pesquisa realizada revelou dados significativos e orientou o planejamento inicial das ações com as famílias, como também o modelo de intervenção a ser adotado após a entrega das unidades habitacionais.

\section{A Prática de Gestão}

O processo de intervenção foi iniciado com a triagem dos futuros moradores e o seu acompanhamento, por meio de atendimento médico e psicossocial, utilizando a metodologia do sociodrama ${ }^{2}$, com objetivo de trabalhar as relações interpessoais e identificar os valores e cultura do grupo com vista a sua reinserção social.

Durante o período da construção das unidades habitacionais, as famílias passaram a morar em imóveis alugados, para tanto foi providenciada a regularização civil das pessoas, para que elas pudessem receber o auxilio moradia. Em contrapartida, participavam de reuniões com uma equipe multidisciplinar, composta por assistente social e psicóloga, para discutirem sobre as etapas do projeto, noções de convivência, participação em espaços coletivos, direitos e deveres e outros temas comunitários.

A partir da parceria com a organização não governamental AVSI/CDM (Cooperação para o Desenvolvimento e Morada Humana) ${ }^{3}$ foi iniciado o processo de pós-ocupação do loteamento, que visava melhorar as condições de vida dos moradores, por meio da promoção do estreitamento das relações sociais, do estímulo ao protagonismo, da melhoria da situação socioeconômica daquela população.

Com os dados quantitativos e qualitativos, resultado da pesquisa realizada no início da construção da intervenção, a organização AVSI/CDM, utilizando a metodologia do Marco Lógico, definiu as ações de caráter emergencial, além de outras atividades que necessitavam de um estudo mais aprofundado da comunidade, no sentido que se pudesse definir estratégias com os diversos atores institucionais e os moradores, que norteariam um planejamento, a médio e longo prazo, com ações objetivas para melhorar as condições de vida da população do Loteamento Moradas da Lagoa e seu entorno. Para tanto, o arranjo institucional e articulação entre os parceiros foram uma condição sine qua non para a garantia da implementação e o acompanhamento dessas ações.

As circunstâncias das famílias beneficiadas - as quais possuíam poucas noções de convivência comunitária e encontravam-se carentes de condições básicas de sobrevivência - 
resultaram em muitas dificuldades para a integração entre os moradores do loteamento e do seu entorno. Brigas frequientes, agressões, cenas de alcoolismo geravam uma situação de maior insegurança, que contribuía para o aumento da desconfiança e o reforço do individualismo, como condição de defesa e sobrevivência.

Ao lado disso, dois fatores precisavam ser enfrentados: o desemprego, presente em todas as famílias, e a própria fome, como sua mais imediata consequiência.

Moradores desistiam de suas casas, outros as vendiam, sem documentação, voltando às ruas e os problemas de toda ordem cresciam. Juntava-se a isso o individualismo e a grande dependência do assistencialismo do Estado, levando as pessoas a esperar soluções e exigir providências, sem participar ativamente da busca de soluções.

Dentre as providências imediatas, a primeira foi trazer para o Loteamento famílias carentes, que moravam em áreas de extremo risco, mas com experiência de moradia em comunidade, o que ajudou a diminuir os atritos entre os assentados no processo de educação para a convivência social. Outra ação importante foi a de buscar a integração com a população do entorno, envolvendo associações comunitárias existentes para iniciarem uma sensibilização quanto à importância da participação em instituições coletivas, buscando iniciar o processo de fortalecimento do capital humano e social. Nesse sentido, a prática social tem como princípio à participação da comunidade, para que esta possa se apropriar do seu espaço geográfico, e que reflita o vivido territorial na sua abrangência e em suas múltiplas dimensões: cultural, política, econômica, social e ambiental, expressando o seu sentimento de pertencimento.

Da questão social, na área urbana das grandes cidades, emerge aspectos, tais como: carência de habitação ou precárias condições de habitabilidade; falta de recursos na saúde e na educação; recursos insuficientes para atendimentos das áreas social e cultural; desemprego ou subemprego (muitas vezes, combinados com qualificações inadequadas às novas formas de organização técnica dos processos de trabalho e produção); crise de estruturas familiares; tensões sociais permanentes sujeitas a explodirem em crises domésticas; e conflitos de vizinhança. Esse contexto é refletido no território de Moradas da Lagoa e seu entorno.

Ações emergenciais compensatórias foram desenvolvidas de início para que respondessem aos sérios problemas econômicos e sociais. Implantou-se no Loteamento, uma cozinha comunitária que distribuía alimentação gratuita para parte da comunidade que apresentava demandas de atendimento médico e psicológico. Aliadas a isso, foram implementadas ações ligadas às áreas de saúde, educação, segurança e de inclusão econômica, através da implantação de hortas comunitárias e apoio financeiro a pequenos negócios; e a inclusão nos programas assistenciais do governo federal.

Foi iniciado nesta ocasião uma experiência de micro-crédito com o financiamento de recursos, na ordem de no mínimo $\mathrm{R} \$ 100,00$ (cem reais) e no máximo $\mathrm{R} \$ 300,00$ (trezentos reais), para aquisição de insumos, com o objetivo de atingir especialmente as pessoas sem nenhuma renda e aqueles que já desenvolviam pequenas atividades como ambulantes. A seleção do candidato ao micro-crédito era feita mediante uma entrevista, onde foram avaliadas as situações socioeconômica e psicológica dessas pessoas e as suas experiências na área mais abrangente e na própria vizinhança. Em contrapartida, cada beneficiário ao micro-crédito teria que participar nas diferentes atividades nas áreas de saúde, alimentação e educação. Foi instituída com pagamento do empréstimo concedido, a restituição da quantia em produtos não perecíveis, que seriam utilizados na alimentação das crianças da creche da comunidade. Como resultados foram concedidos 130 empréstimos, com a inadimplência de apenas $2 \%$. A fiscalização dos pagamentos dos empréstimos era feita pela própria vizinhança e os pais dos alunos da creche. 
Apesar do sucesso inicial da experiência piloto, o projeto não pode continuar por falta de apoio de instituições de micro-crédito, que geralmente possuem procedimentos para a aquisição do empréstimo incompatíveis com as condições dessa população.

Nesse cenário, a economia solidária seria uma estratégia para aquisição do crédito, através do aval solidário, a implementação de clubes de trocas ou a utilização de uma moeda social ou solidária. No entanto, essa população não possui, ainda, fortes laços de proximidade e vizinhança, como também carecem do fortalecimento comunitário para implementação dessa estratégia.

Atualmente, a comunidade conta com os seguintes equipamentos sociais: creche, escola municipal, módulo policial, um infocentro e um centro comunitário para realização de atividades culturais, de lazer, treinamentos, oficinas, reforço escolar, reuniões com a associação local de moradores, já constituída legalmente.

A Associação de Moradores de Moradas da Lagoa - AMCHAMOLA foi constituída e já está legalizada com o objetivo de defender os interesses da comunidade nas áreas de saúde, educacional, social, econômica e ambiental da comunidade; e articular parcerias institucionais para a consecução das ações operacionais que visem à melhoria da qualidade de vida da população, a afirmação da cidadania e o fortalecimento comunitário. A diretoria da AMCHAMOLA se reúne regularmente às segundas e quartas-feiras no Centro Comunitário do Loteamento, sendo que, às quartas-feiras, a reunião é aberta aos associados, convidados e visitantes. Tem sido observado o aumento da representatividade na comunidade, além do crescente amadurecimento no processo de organização comunitária. A participação dos moradores do Loteamento nas reuniões ordinárias da associação é intensa e vem sendo ampliado o processo de negociação dos pleitos da comunidade com representantes das instituições competentes.

Todo o processo de condução da prática social tem sido pautada na metodologia participativa, tendo como princípio que a participação é possível, que é fundamental na consolidação da democracia e no fortalecimento do capital social. Neste particular, é relevante a consideração de Pires (2001) ao discorrer sobre Orçamento Participativo, sendo que a metodologia participativa possibilita operacionalizar na prática os conceitos abstratos da participação.

No entanto, tem-se a consciência de que nem "tudo são flores" muitas vezes idealizado no mundo da participação, pois, a todo momento são vivenciadas disputa de poder, conflitos, interesses pessoais e institucionais, radicalizações de posições e atitudes autoritárias, cabendo aos gestores sociais (que estão conduzindo e mediando esse processo) a busca de estratégias que facilitem as relações interpessoais e as relações intra e inter organizacionais, construindo acordos e consensos. Os instrumentos participativos têm como função principal ajudar a estruturar às disputas sobre poder entre os atores estratégicos, parceiros do Projeto, a torná-los mais transparente e, dessa forma, contribuir para uma distribuição mais eqüitativa do poder.

Markus Brose, no seu livro Metodologia Participativa, apresenta que muitos autores defendem a linha de argumentação segundo a qual, na relação entre população, organizações da sociedade civil, órgãos governamentais e setor privado, não há possibilidade para uma verdadeira participação. Segundo esse raciocínio, os técnicos que utilizam a metodologia participativa não são ingênuos e mesmo imbuídos das melhores intenções, cooptam a população para os interesses da elite dominante.(Brose, 2001).

Para que sejam concretizados os canais de participação, estes devem estar contidos nos espaços de discussão e negociação das políticas públicas, que, em verdade são "espaços de explicitação de conflitos e interesses, contrários, portanto, a qualquer idéia de processo harmonioso de delegação de poderes" (Nogueira, 2004, p. 161).

A gestão participativa envolve intensas demandas e pressões sobre o governo, que precisa ter uma visão sistêmica da complexidade inerente aos processos democráticos, 
articulando projetos de curto, médio e longo prazos. O Estado, burocrático e paternalista, ainda não consegue articular respostas positivas em tempo hábil no tempo da globalização, e dos problemas prementes do capitalismo exacerbado. A descontinuidade e a falta de integração dos programas sociais e produtivos fomentados pelas políticas públicas ainda se constituem como obstáculos no planejamento democrático e na efetiva medida de emancipação política.

Amenizados os problemas iniciais da pós-ocupação relatados na prática de gestão, onde foi desenvolvido um trabalho com as famílias, a articulação de novos parceiros, e a organização comunitária (por meio do estreitamento das relações de confiança da população), um novo desafio estava colocado, tão importante quanto o que já se havia conquistado: Como fomentar a geração de emprego e renda para a comunidade, de forma sustentável?

\section{Transformação do mundo do trabalho}

A globalização e o neoliberalismo trouxeram mudanças nos padrões de produção. As relações do trabalho sofreram as influências das transformações socioeconômicas, que reafirmaram o lado perverso do capitalismo, constituindo-se como um sistema instável, cíclico, com crises, incapaz de resolver o problema básico de sobrevivência humana, a fome, e agravando um outro problema crucial: o desemprego. Ratificando este cenário Ianni afirma: "Sob as mais diversas formas sociais e técnicas de organização, o processo de trabalho e produção passou a estar subsumido aos movimentos do capital em todo o mundo". (2004. p. 124).

A globalização traz ao âmbito local dificuldades cotidianas representadas pela escassez real de recursos, bem como o aumento da incerteza e da insegurança que bloqueiam a interação dinâmica dos indivíduos, freando a criatividade e reforçam rotinas improdutivas. Como reação, temos o aumento da angústia e ansiedade, da inquietação e rebeldia, traduzida, muitas vezes, no aumento da violência.

Diante desse quadro estrutural, faz-se necessário buscar novos processos de desenvolvimento que possam aliar o "global" ao "local", buscando refletir a regionalização dos espaços e relações sociais de cooperação e conflitos, numa nova lógica e racionalidade, onde o foco seja na melhoria da qualidade de vida do ser humano. Busca-se, assim, a racionalidade substantiva, na qual se valorizam as relações interpessoais e interorganizacionais, no intuito da cooperação e da solidariedade, fundamentada no conceito de pertencimento ao âmbito local/territorial.

Pensando nisso, buscou-se fomentar ações produtivas tentando aliar duas vertentes. Por um lado, atrair um complexo de indústrias urbanas não poluentes que pudesse se instalar no território, criando empregos para a comunidade de Moradas da Lagoa e seu entorno. Por outro lado, incentivar as vocações empreendedoras individuais e coletivas, formais e informais, através de apoio financeiro para aplicação na montagem de um pequeno negócio ou em capital de giro para uma iniciativa já existente.

Em 2004, o Governo do Estado, através das Secretarias de Combate à Pobreza e às Desigualdades - SECOMP; de Indústria, Comércio e Mineração - SICM e da Superintendência de Desenvolvimento Comercial e Industrial - SUDIC, assinaram um protocolo de intenções para a implantação de um condomínio de 14 fábricas urbanas não poluentes no Loteamento Moradas da Lagoa. Esse conjunto de fábricas vai absorver, até dezembro de 2007, cerca de 2 mil trabalhadores do Loteamento e do seu entorno (Coutos e Valéria), nos setores de metalurgia, material de limpeza e higiene, confecção, eletroeletrônicos, tapeçaria e movelaria. 
No processo de articulação e negociação com o setor privado, observam-se relações de conflito e cooperação, que estão proporcionando o exercício de construção de uma experiência conjunta do governo com as empresas privadas, a sociedade civil organizada e a comunidade. Nesse sentido, a partir dos processos de cooperação e de conflito, houve reestruturação na forma de condução, elaboração e desenvolvimento das ações do Projeto.

$\mathrm{Na}$ contratualização entre o Governo do Estado e as empresas privadas, foram estabelecidos alguns critérios a serem assumidos pelo setor privado: (i) contratação de um número de trabalhadores compatível com o tamanho físico do galpão; (ii) não discriminação por idade e sexo, a não ser em casos específicos onde as atividades profissionais exijam esta diferenciação; (iii) $80 \%$ das contratações devem contar com moradores do território (Moradas da Lagoa, Coutos e Valéria); desenvolvimento de ações e projetos sociais na comunidade; (iv) incentivo à qualificação profissional e à escolarização dos trabalhadores; (v) processo de seleção com os trabalhadores; (vi) constituição de uma equipe multidisciplinar que desenvolva, com os trabalhadores, ações de relações interpessoais, relações no trabalho, direitos e deveres empregatícios e cidadania.

O Estado ficou responsável pela: (i) prospecção e articulação com as empresas; (ii) construção dos galpões e assinatura de um contrato de comodato por 10 anos com as empresas; (iii) capacitação técnica dos futuros contratados, para que o conteúdo pragmático e a metodologia de atuação das instituições contratadas sejam ajustados às dificuldades de escolaridade da população.

Durante a contratualização, algumas empresas foram retiradas do processo por não atenderem aos critérios técnicos acordados. É importante ressaltar a dinâmica das relações com as respectivas escalas de poder entre a comunidade, empresas privadas e governo estadual, nas quais se experimentam avanços, retrocessos, cooperação, conflito, compartilhamento, posturas autoritárias, competição, solidariedade. Essas dualidades estão inseridas no contexto neoliberal do capitalismo, que vem passando por um processo de mudança nas relações de produção, com a flexibilização dos processos, de trabalho, dos mercados, dos produtos e padrões de consumo, as inovações tecnológicas e organizacionais.

O mercado de trabalho sofre impactos dessa reestruturação, facilitados pela fragilidade do movimento sindical frente ao crescente desemprego. O processo de reestruturação promove a redução do emprego regular, abrindo espaço para o trabalho temporário ou subcontratado, bases da chamada precarização.

Algumas empresas que serão instaladas no Condomínio Empresarial Moradas da Lagoa já desenvolvem ações de Responsabilidade Social e outras estão sensibilizadas a iniciar esse processo. Nesse sentido, o Estado vem buscando estreitar os laços do empresariado com a comunidade, para que o setor privado possa cumprir a sua responsabilidade enquanto parceiro do Projeto, contribuindo para o desenvolvimento comunitário do espaço territorial.

Sabe-se que a gestão privada possui uma finalidade econômica condicionada a uma racionalidade instrumental, que torna as relações mercantis, definidas numa base técnica de custo-benefício, em primazia ao social, ao cultural e ao ambiental. No entanto, essas organizações, mesmo atuando no espaço do chamado mercado, estão sendo mobilizadas a contribuir em favor de práticas de gestão social, cultural e educacional, humanizando suas relações de trabalho e produção.

A participação das empresas privadas com investimento social em organizações da sociedade civil e, mais especificamente, nos empreendimentos populares, passa a ser um diferencial competitivo para as empresas que investem na área social, através de ações práticas com seu entorno, sua cadeia produtiva, com a comunidade em que está inserida e com o ambiente como um todo.

Numa outra vertente de produção e trabalho, o Estado vem fomentando núcleos de produção coletiva, através de grupos de moradores e formação de associação e cooperativas 
solidárias. Um exemplo é o núcleo produtivo de uma fábrica de biscoitos, que irá beneficiar diretamente 20 pessoas na produção e mais 40 pessoas no setor de vendas. Esse projeto é fruto de uma parceria com a Companhia de Eletricidade do Estado da Bahia - COELBA ${ }^{4}$, através das áreas de responsabilidade social e eficiência energética da empresa, e a Associação Gente do Brasil ${ }^{5}$, que escolheu a comunidade de Moradas da Lagoa, para investir recursos numa ação produtiva coletiva, denominado Projeto Energia Produtiva. Essa Associação é a responsável pelo acompanhamento do projeto por dois anos, período em que será constituída uma cooperativa na lógica da economia solidária, através do apoio financeiro da SECOMP e da COELBA.

A proposta geral do Projeto Energia Produtiva é o desenvolvimento e adaptação de metodologias de geração de emprego e renda em comunidades carentes, tendo a energia como vetor das ações. A primeira ação da Associação Gente do Brasil, junto aos moradores da comunidade, buscou identificar pessoas que pudessem ser treinadas e estimuladas a desenvolver o espírito empreendedor e cooperativo. Para tanto foi realizada, após reuniões de sensibilização, uma seleção daqueles que representarão o grupo gestor do empreendimento solidário. Iniciou-se a pré-seleção do referido grupo por meio de aplicação de questionário e entrevistas semi-estruturadas a cerca de duzentos candidatos, todos desempregados.

Inicialmente selecionaram-se treze pessoas, que participaram de treinamento motivacional, de liderança e trabalho em grupo. Posteriormente, esse grupo, mediante exercícios de avaliação de negócios, definiu que a alternativa de empreendimento de maior chance de sucesso considerando suas características, localização e competências, seria a fabricação de sequilhos e biscoitos. A partir disso, os futuros cooperados passaram por um treinamento técnico profissional, através de parceria celebrada com o SENAI - Serviço Nacional de Aprendizagem Industrial, sendo capacitados na produção de sequilhos e biscoitos de acordo com os padrões adequados de higiene, qualidade e segurança, além dos conhecimentos teóricos, práticos e comportamentais.

A COELBA atuou na viabilização financeira do treinamento e das máquinas e equipamentos necessários, participando, também, com informações ao grupo sobre economia e eficiência no uso da energia. O outro parceiro do Projeto, a SECOMP, viabilizou o terreno e a construção da Fábrica de Biscoitos, através da SUDIC- Superintendência de Desenvolvimento Comercial e Industrial, responsável pelo projeto arquitetônico e operacionalização das obras civis. O empreendimento possui uma área total de $142 \mathrm{~m}^{2}$, abrigando além da área de produção, uma loja para venda direta, escritório de administração, vestuários e sanitários.

Visando suprir a necessidade de treinamento na área de gestão, na lógica da economia solidária, os parceiros envolvidos no projeto estão financiando capacitação em empreendedorismo e cooperativismo, utilizando a metodologia participativa, para realização do plano de negócio e construção do modelo de gestão da cooperativa.

Foi firmada, também, uma parceria com o Banco do Brasil, com vistas à obtenção de um fundo de investimentos, compatível com a capacidade do projeto. Isso foi possível dada a intervenção da COELBA, que garantiu um arranjo financeiro especial.

Em 2006, verificou-se a consolidação de algumas ações: implantação de uma horta orgânica comunitária; apoio à formação de uma cooperativa de cozinheiras; de lapidadores de pedras; parceria com instituições de crédito solidário, para o fortalecimento de pequenos negócios; intensificação das ações de organização comunitária e educação ambiental, alfabetização de adultos; implantação de um infocentro; apoio a núcleos produtivos de confecção, reciclagem, trabalhos manuais e artesanato.

A horta comunitária orgânica é formada por 32 famílias, distribuídas numa área de 10 mil $\mathrm{m}^{2}$. O processo de associativismo vem sendo desenvolvido com o apoio técnico de uma equipe multidisciplinar composta por um engenheiro agrônomo, uma assistente social e uma 
socióloga que acompanham as famílias, considerando como aspectos básicos: a formação cidadã e a capacitação em instrumentos técnicos e de gestão de tipo solidário, baseado nos pressupostos da Economia Solidária. Trata-se de uma economia centrada no ser humano (e não no capital), de bases associativa e cooperativista, voltadas para a comercialização de bens e serviços, de modo autogerido, fortalecendo a economia local.

Os processos produtivos oriundos da sociedade civil organizada e fundado prioritariamente nas relações comunitárias têm sido fomentados no Projeto Morados da Lagoa, tentando interagir com o mercado capitalista. As características dos empreendimentos solidários demandam um acompanhamento diferenciado em termos de gestão, tanto pelo seu caráter participativo para todos os membros, como nos valores de cooperação que lhes são inerentes, que diferem dos pressupostos econômicos majoritários, mas são amplamente praticados no meio popular.

Os fenômenos associativista e cooperativo são apresentados como elementos possibilitadores de inclusão social e do bem comum, que se traduzem em desenvolvimento local. Parte da idéia que o associativismo e a cooperação contêm o desenvolvimento, na medida em que este acontece na perspectiva de melhorar as condições sócio-econômicas locais, considerando-se todas as suas dimensões. Assim, "Indivíduos se associam em função de interesses comuns que podem desencadear ações de cooperação com reflexo no desenvolvimento local" (Frantz, 2002, p.2).

Essas diferentes experiências econômicas que evoluem em atividades de pequena escala, com pequenos negócios, prestação de serviços, cooperativas e microempresas de produções familiares, artesanais, compõem o que se denomina economia popular ou economia solidária, que podem "representar germes de uma nova cultura do trabalho" (Tiriba, 1997, p.20).

A economia popular ou economia solidária pode representar a oportunidade de (re) integração dos excluídos do processo de produção, "o que poderá recolocar a competição sistêmica, ou seja, a competição entre um modo de produção movido pela concorrência inter capitalista e outro movido pela cooperação entre unidades produtivas de diferentes espécies, contratualmente ligadas por laços de solidariedade" (Singer, 1997, p.13).

O Estado tem um importante papel na inclusão socioeconômica dos empreendimentos populares ou solidários, tendo como desafio desenvolver políticas públicas que estimulem alternativas autônomas e em autogestão popular para a geração de trabalho e renda, para o acesso ao micro-crédito, democratizando a possibilidade das comunidades mais carentes a instrumentos que lhes permitam uma cidadania e uma inserção ativas. O estímulo à autogestão popular, expressa comumente no chamado empreendedorismo popular, tem surgido nas formas mais variadas da chamada economia popular solidária (associações, cooperativas, redes de comércio solidário, empresas de autogestão, etc.).

Vale ressaltar que os empreendimentos populares ou solidários possuem uma dinâmica híbrida, que combina a produção doméstica de valores de uso com as relações de produção mercantil, aceitando-se o desafio de construir uma alternativa a partir dessas relações, ainda que não mais ao capitalismo, mas no capitalismo, de resistência à lógica mercantil que preside a sociabilidade contemporânea, assentando as possibilidades para construir, a longo prazo (porém aqui e agora) as condições para uma nova sociedade.

De acordo com Corraggio, na sua conferência sobre Economia do Trabalho realizada na Fundação Luís Eduardo Magalhães, é possível o desenvolvimento, como sentido estratégico das práticas populares e também estatais, em uma construção coletiva, que não está pronta ainda, mas em processo e sua consolidação, que, no imaginário coletivo e na realidade, requer dois elementos fundamentais. O primeiro é que, no contexto capitalista neo-liberal, a população desempregada não terá possibilidade de inclusão no processo produtivo tradicional. Portanto, teremos que buscar outras alternativas. Segundo, que possamos recuperar, na história da América Latina, as práticas de organizações de economia popular, nas 
comunidades étnicas, nas associações mutuas de trabalhadores assalariados, nas formas autogestionárias, nas formas de cooperação formal ou baseada nos costumes (Caderno de Economia Solidária, FLEM- 2003).

Ao resgatar valores e práticas que se encaminham para o exercício de uma ética calcada numa solidariedade consciente, as práticas que se espelham nos princípios da economia solidária contribuem para a auto-estima do grupo de trabalhadores associados, bem como da sua família, e da sua comunidade. Respeitando também o tempo de caminhada de cada núcleo produtivo, as ações solidárias propiciam a reintegração de saberes que o capitalismo fragmentou, articulando-os às práticas cotidianas de vida e trabalho, de maneira a favorecer o nexo entre ação/reflexão/ação, estimulando a criação de novos conhecimentos que possam ressignificar valores e práticas sociais.

O conhecimento pertinente deve enfrentar a complexidade e o seu caráter multidimensional, inserindo outras dimensões que não seja apenas a econômica, tais como: a sociológica, a histórica, a psicológica , a política, a religiosa; fazendo com que essas dimensões possam interagir na multiplicidade, buscando trabalhar os desafios da complexidade humana (Morin, 2001).

A complexidade humana não poderia ser dissociada dos elementos que a constituem: "todo desenvolvimento verdadeiramente humano significa o desenvolvimento conjunto das autonomias individuais, das participações comunitárias e do sentimento de pertencer à espécie humana" (Morin. 2001, p.55).

\section{Considerações finais}

De acordo com Ianni (2004, p.11), a globalização é abrangente, complexa e contraditória. "Uma realidade ainda pouco conhecida, desafiando práticas e idéias, situações consolidadas e interpretações sedimentadas, formas e pensamentos e vôos de imaginação" Assim, entender e articular o global com o local é um dos desafios da prática sócio territorial.

Sabe-se que ainda existe um longo caminho a percorrer na busca do desenvolvimento inclusivo dos cidadãos e, para tanto, é necessário o fortalecimento enquanto individuo e de forma coletiva nas organizações sociais, que darão acesso à participação política e ampliação dos espaços públicos democráticos.

A democracia deve garantir a oportunidade plena dos cidadãos, através de acesso aos direitos civis, cívicos, políticos, onde os cidadãos devem formular e expressar suas preferências de forma individual e/ou coletiva e ter a garantia de que suas preferências serão consideradas sem discriminação, por meio da implementação de políticas públicas participativas.

Nesse sentido, de acordo com Oliveira a cidadania não pode ser mensurada apenas como melhoria da qualidade de vida. "Refere-se ao indivíduo autônomo, crítico e reflexivo, longe, portanto, do indivíduo-massa; trata-se de uma aquisição por meio do conflito" (Programa Gestão Pública e Cidadania/FGV-EAESP.336p.).

Com o avanço da democracia, é ampliada a noção de inter-relação entre o público e o privado, sendo que, em alguns momentos, os interesses diversos interagem nos espaços onde os agentes social e do desenvolvimento, públicos e privados, interpenetram-se de forma que é difícil identificar seus limites.

$\mathrm{Na}$ estratégia de desenvolvimento, a nova gestão pública requer a inclusão de diretrizes que dêem conta da complexidade de situações existentes, tornando obrigatória a aproximação territorial, a fim de se obter o estímulo à negociação entre atores locais, públicos e privados (prefeituras, centros de capacitação, universidades, associações, empresas, sindicatos, 
organizações cívicas, etc.), com o propósito de melhorar a vinculação desses atores, em rede, e aumentar a cooperação, as parcerias e as alianças.

As relações interorganizacionais acontecem no espaço público, co-habitado e impactado por agentes com características diferentes, mas com certos objetivos em comum, por isso o binômio cooperação/conflito está sempre presente. É necessário compartilhar as competências para enfrentar os desafios da atualidade. Nesse sentido, as organizações não são entidades autônomas. São, ao contrário, âncoras em meio a redes de interações com outras organizações, do mesmo ou de diferentes setores. Neste sentido, cooperação e conflito são processos simultâneos em relações interorganizacionais, representando tentativas de promoção da igualdade de oportunidade com mais criatividade; mas, ao mesmo tempo, de maiores conflitos.

Para promover a igualdade de oportunidades, através da cidadania, é necessário democratizar o acesso a bens e serviços como moradia, transportes, ambiente urbano, educação e saúde, concomitante com a participação ativa e autônoma dos indivíduos e grupos.

A cidadania ativa, bem apresenta por Nogueira, "é uma condição essencialmente política: seus protagonistas concebem o mundo como um ambiente de direitos e responsabilidades recíprocas e se realizam nele como sujeitos de vontade e de ação coletivamente construídos" (Nogueira, 2004, p. 62)

Essa experiência de gestão em "Moradas da Lagoa" está em processo de construção e reconstrução cotidiana, onde não existem modelos próprios ou pré-definidos, podendo-se considerá-la inovadora, na medida em que se vem adotando uma políticas de ações integradas com as famílias, considerando o caráter multidimensional do ser humano, numa perspectiva de socialização e de construção do sentimento de pertencimento.

A intervenção está pautada numa metodologia participativa, vivenciando as lógicas das relações de poder, num campo de disputas, no qual a correlação de forças, a movimentação social e a organização política dos interesses dos atores estratégicos (envolvidos na experiência) têm papel decisivo. O Estado, enquanto espaço de regulação, elaboração e implementação de políticas públicas, precisa ser assimilado como parâmetro ético de convivência e locus para o encontro de soluções positivas para os problemas sociais (Nogueira, 2004).

O Estado deve ser o propulsor do vetor da democracia participativa, estabelecendo relações de reciprocidade com a sociedade civil que possam propiciar novas oportunidades de justiça social redistributiva e de participação política. No entanto, essa discussão não pode estar descolada do contexto da globalização, onde muitas vezes a soberania do Estado passa a ser tutelada ou regulada pelas estruturas globais do poder ou mesmo pela "lógica" da economia mundial, dominada pelos grupos econômicos internacionais.

Ratificando esse pensamento, Boaventura de Sousa Santos, refere-se ao "Estado como novíssimo movimento social", abordando o seu papel como articulador e coordenador de um conjunto híbrido de fluxos e redes que se integram e se interpenetram, na busca da democracia redistributiva e participativa, atuando com os agentes privados, empresas, organizações não governamentais e movimentos sociais (apud Oliveira e Peoli, 1999).

A partir do relato dessa experiência é importante levantar algumas questões: (i) Existe um único tipo de estratégia de desenvolvimento em um território? (ii) Pode a economia solidária se desenvolver inter-relacionando com a economia de mercado capitalista globalizada? (iii) A metodologia participativa cidadã pode acontecer de forma verdadeira no modelo neoliberal de desenvolvimento? (iv) As dualidades cooperação/conflito; competição/solidariedade; democracia/autoritarismo; racionalidade instrumental/racionalidade substantiva estão sempre presentes nas práticas de gestão social?

Considerando-se que "a democracia constitui (...) um sistema político complexo, no sentido de que vive de pluralidades, concorrência e antagonismos, permanecendo como 
comunidade" (Morin, 2001, p.108), as respostas concretas às supracitadas indagações dependerão não somente da participação dos cidadãos envolvidos no processo - como pessoas individualmente consideradas -; mas de um fortalecimento, cada vez maior, do sentido de ação comunitária integrada (como se apreende do exemplo de "Moradas da Lagoa"), com vistas ao fortalecimento das bases democráticas (tão essenciais à continuidade das ações sustentáveis do desenvolvimento social e humano). Eis o desafio posto.

\section{Referências}

BROSE, Markus. Metodologia Participativa: uma introdução a 29 instrumentos. Markus Brose (Org.). - Porto alegre: Tomo Editorial, 2001.

CADERNOS DA FLEM. Economia Solidária: desafios para um novo tempo. Fundação Luís Eduardo Magalhães - Salvador: FLEM, 2003. 132p.

CACCIO-BAVA, Silvio; PAULICS, Veronika; SPINK, Peter. (orgs). Novos contornos da gestão local: conceitos em construção. São Paulo, Polis; Programa Gestão P, 1990.

FRANTZ, Walter. Desenvolvimento local, associativismo e cooperação. Conferência apresentada no Simpósio Internacional de Gestão pública. 2002.

IANNI, Octavio. Teoria da Globalização. Rio de Janeiro: Civilização Brasileira, 1966.

KLISBERG, Bernardo. Falecias e mitos do desenvolvimento social. 2. ed. São Paulo: Cortez; Brasília, DF: UNESCO, 2003.

MORIN, Edgar. Os sete saberes necessários à educação do futuro; tradução de Catarina F. da Silva e Jeanne Sawaya. 4. ed. São Paulo: Cortez; Brasília, DF: UNESCO, 2001.

NOGUEIRA, Marco Aurélio. Um Estado para a sociedade civil: temas éticos e políticos da gestão democrática. São Paluo: Cortez, 2004.

OLIVEIRA, Francisco e PEOLI, Maria Célia (org.). Os sentidos da democracia. Petrópolis. Ed. Vozes, 1999.

PIRES, Valdemir. Orçamento Participativo: para que serve, como se faz. Barueri: Maonole, 2001.

SANTOS, Milton. A urbanização brasileira. $3^{\text {a }}$ edição. São Paulo: Hucitec, 1996

SINGER, Paul. Introdução à Economia Solidária. $1^{a}$ ed. São Paulo: editora Perseu Abramo, 2002.

TIRIBA, Lia Vargas. Organizações Econômicas Populares: desvelando contradiçõess e desafios de estratégias populares de geração de trabalho e renda. Relatório de Pesquisa. (Mineorg.). Cooparg. Cooperaativa de Produção de parafusos do Rio de Janeiro. Proposta, n.74, set./nov.,p. 64-74,1977.

ESTUDO DE CASO. Maridalva Dantas dos Reis. Loteamento Moradas da Lagoa: Uma experiência de ação integrada. Monografia do Curso de Especialização em Gestão Social para o Desenvolvimento. UFBA: Escola de Administração.

RELATÓRIOS. Moradas da lagoa: Projeto de Pós-ocupação. Associação Voluntários para o serviço Internacional - AVSI (Org.). 2003 / 2004 / 2005.

\footnotetext{
Notas

${ }_{1}$ Graduada em Serviço Social pela Universidade Católica do Salvador - UCSAL; Especialista em Psicodrama e em Gestão Social para o Desenvolvimento; mestranda do Mestrado
} 
Profissional e Multidisciplinar em Desenvolvimento e Gestão Social pela Universidade Federal da Bahia - UFBA, Escola de Administração; Servidora Pública, Coordenadora de Ações Sócio-produtivas da Secretaria de Combate à Pobreza e às Desigualdades Sociais da Bahia e atualmente atua no Núcleo de Desenvolvimento do Ser Humano- NDSH, Secretaria Estadual da Fazenda - SEFAZ/BA.

2 Sociodrama: Método de psicoterapia de grupo, criado pelo Austríaco J.L.Moreno, em 1914. Este método procura estabelecer uma ponte entre a psiquiatria e as ciências sociais, utilizando técnicas de desempenho de papéis nas relações sociais, utilizando as interpretações das ações cotidianas e das imagens como referenciais para o desenvolvimento da espontaneidade e criatividade.

${ }^{3}$ AVSI - Associação Voluntários para o Serviço Internacional é uma ONG criada na Itália em 1972, formalmente reconhecida pelo Ministério das Relações Exteriores da Itália e pela Comunidade Européia. A AVSI constitui hoje uma rede internacional de ONG's associadas, de norte a sul em todo mundo e participa do Conselho Econômico das Nações Unidas, colaborando nas realizações de intervenções e cooperação para o desenvolvimento de comunidades carentes. No Brasil a AVIS vem atuado junto a CDM - Cooperação para o Desenvolvimento e Morada Humana - ONG brasileira que tem por finalidade o desenvolvimento de programas nos âmbitos econômicos, social, urbanístico-ambiental, cultural, educativo e formativo visando a promoção integral da pessoa humana e das comunidades onde atua,

${ }^{4}$ COELBA - Companhia de Eletricidade do Estado da Bahia, através do Programa de Responsabilidade Social Empresarial - "Energia para Crescer", vem desenvolvendo ações que estejam vinculadas aos princípios de responsabilidade social corporativa, materializado na sua missão, com o compromisso do desenvolvimento sócio-econômico sustentável do Estado e da melhoria do clima organizacional e a relação com a sociedade. O Programa elege quatro focos de atuação: educação, meio ambiente, cultura e projetos produtivos ligados à distribuição de energia elétrica.

${ }^{5}$ Associação Gente do Brasil: Fundada em setembro de 2003, surgiu como resultado de estratégias e propostas elaboradas na prestação de serviços ao Programa de Energia da Agência Norte - Americana para o Desenvolvimento Internacional - USAID, tendo a missão de incentivar o uso produtivo de energia como vetor de desenvolvimento e proporcionar capacitação, aperfeiçoamento, integração profissional e geração de emprego e renda como ferramentas para o benefício da sociedade e do meio ambiente. 